\title{
UM OLHAR SOBRE O MUITO(A) NO PORTUGUÊS BRASILEIRO: O CASO (OU NÃO) DA AMBIGUIDADE
}

\author{
The use of muito(a) in Brazilian Portuguese: the ambiguity case (or not)
}

\author{
Kayron Campos Beviláqua \\ Mestrando do Programa de Pós-graduação em Letras da \\ Universidade Federal do Paraná - Estudos Linguísticos (UFPR) \\ Pesquisador do Núcleo de Estudos Gramaticais - \\ Universidade Federal de Santa Catarina (NEG - UFSC) \\ kayronbevilacqua@hotmail.com
}

\begin{abstract}
RESUMO: Neste artigo analisamos os usos do quantificador muito(a) associado ao sintagma nominal nu singular no Português Brasileiro (PB). Para isso, fazemos um paralelo com o que parece ser o quantificador plural no $\mathrm{PB}$ - muitos - e também seus correspondentes no inglês (much e many). Para tentar entender que tipo de comparação é realizada pelo muito(a), trazemos para a discussão o artigo de Bale \& Barner (2009), mostrando que as generalizações feitas por esses autores não se aplicam aos dados apresentados. Por último, concluímos que muitos é um quantificador especializado para predicados plurais e desenvolvemos argumentos para um tratamento não ambíguo do muito no PB.

PALAVRAS-CHAVES: Massa; Muito; Português Brasileiro; Quantificadores; Singular nu.
\end{abstract}

ABSTRACT: This paper analyses the different uses of muito (a) as a quantifier over bare singulars in Brazilian Portuguese. We make a comparison between the plural quantifier in Brazilian Portuguese (muitos) and the quantifiers much and many in English. We also discuss the Bale \& Barner's (2009) theory, showing that their predictions do not hold for Brazilian Portuguese. Then, we conclude that muitos is a plural quantifier and we develop some arguments against the ambiguous treatment for the quantifier muito.

KEYWORDS: Mass; Muito(a); Brazilian Portuguese; Quantifiers; Bare singulars.

\section{INTRODUÇÃO}

Neste trabalho, analisaremos os diversos usos do quantificador muito(a) associado ao sintagma nominal nu singular no PB. Descritivamente, o singular nu - a versão abreviada de sintagma nominal nu singular - é um sintagma sem determinante aparente, sem marca de pluralidade. Pires de Oliveira \& Rothstein (2011) levantam, pela primeira vez, a hipótese de que esse sintagma ocorre também com quantificadores e sintagmas de medida. A partir disso, vamos investigar essa questão olhando-a através do comportamento de muito. 
O muito(a) parece ter propriedades bastante peculiares, pois se combina tanto com nomes que a literatura especializada considera como massivos, como com nomes considerados contáveis. ${ }^{1}$ Vejamos os exemplos abaixo:

(1) Júlio desperdiçou muita água. (volume)

(2) João carregou muita árvore. (unidade e volume)

Em (1), temos o quantificador muita, que está operando sobre água, um nome massivo. O sintagma água não pode ser contado ou medido diretamente numa escala cardinal (isto é, na qual unidades estão disponíveis) porque é um nome de massa, para tanto ele precisa se combinar com um sintagma de medida (ou um classificador), como volume ou litros. Já na sentença em (2), o muita está quantificando um nome que é aparentemente contável e singular, árvore. A interpretação preferencial da sentença em (2) é de que há unidades contáveis de árvore e que o João as carregou. Essa é a interpretação que indicamos por 'unidade'. Dizemos interpretação preferencial porque ela não é a única possível.

Perceba que também é possível a interpretação massiva de sentenças como em (2). Clarificando um pouco a interpretação massiva: imagine que, no contexto em que (2) é proferida, o que está em questão não são as unidades de árvores, mas sim outros aspectos, como volume, peso, ou altura, etc. João carregou muita árvore pode, portanto, ser dito quando João carregou uma porção de árvore que não é passível de contagem, mas que representa algo acima do esperado numa determinada escala de volume ou de peso. Nesse caso, não interessa quantas unidades de árvore o João carregou, mas o volume ou peso de árvore. Ele pode, inclusive, ter carregado uma grande quantidade de árvore, não importando suas unidades. Temos, portanto, dois usos e interpretações distintas para um mesmo item lexical.

O muito(a) também se combina com nomes de massa naturalmente atômicos, isto é, formados a partir de unidades, como é o caso de nomes como mobília, bagagem, prataria, etc.

(3) ??Comprei duas mobílias. (classificador)

A interpretação da sentença em (3) é possível se supomos um classificador, por exemplo, dois conjuntos de mobília.

Mas quando temos uma sentença com muita a leitura contável está disponível:

(4) O João tem muita mobília em casa. (unidade e volume)

Ao proferir a sentença em (4), o falante pode querer se referir a diferentes unidades de mobília que João tem, como mesa, cadeira, etc. A sentença também admite leitura de volume, quando não importam as unidades, mas sim o volume do mobiliário para um determinado espaço, por exemplo. A sentença em (4), portanto, admite tanto a leitura de unidades de mobília quanto de volume.

\footnotetext{
${ }^{1}$ A distinção massivo/contável no sintagma nominal é controversa. Ver, por exemplo, GILLON (1992), CARLSON (1998), ROTHSTEIN (2010).

Work. Pap. Linguíst., 13(1): 51-64, Florianópolis, jan./mar, 2013
} 
Nesse momento, algumas questões se fazem pertinentes: Seria então o muito(a) um quantificador ambíguo, que pode quantificar tanto sobre nomes contáveis quanto sobre massivos a depender do contexto? Ou seriam os nomes ambíguos entre contável e massivo? Podemos aventar outra hipótese para o caso do muito(a) no PB? Para responder essas questões devemos olhar para o tipo de comparação efetuada pelo muito(a) e percebermos que critérios estão sendo mobilizados na comparação. $\mathrm{O}$ objetivo deste trabalho é, então, verificar a interpretação de sentenças, como as apresentadas acima e discutir a possibilidade de uma hipótese ambiguista, mostrando que, apesar de ser uma saída possível, não é a mais econômica. Assim, construímos argumentos contrários à hipótese de ambiguidade para o muito(a), comparando-a à proposta de Pires de Oliveira e Souza (no prelo), que, para o caso da comparação e da combinação com quantificadores como o muito, assume que o singular nu denota espécie e é, portanto, um predicado raiz, em que não há uma unidade definida, nos termos de Pires De Oliveira e Rothstein (2011).

Para discutir as questões aqui brevemente apresentadas, dividimos este artigo em quatro seções. Na primeira seção, fazemos uma descrição dos usos do muito que iremos analisar e também um paralelo entre o muito e o que parece ser a forma plural no PB muitos - e também seus correspondentes no inglês. Essa comparação pode revelar aspectos do muito no $\mathrm{PB}$. Na segunda seção, discutimos o teste da comparação proposto por Bale e Barner (2009) e as generalizações propostas, demonstrando que não se aplicam aos nossos dados. Na seção seguinte, descrevemos a hipótese do muito(a) como ambíguo e expomos argumentos contra essa hipótese, como também apontamos para a hipótese baseada em Pires de Oliveira e Souza (no prelo). Por fim, as conclusões de nossa pesquisa.

\section{MUITO/MUITOS X MUCH/MANY}

Primeiramente, seguindo a literatura (CRESSWELL, 1976; KLEIN, 1980), entendemos que o muito atua numa escala de graus. Semanticamente, há uma propriedade de gradação: uma escala ordenada em graus e um seletor que determina o grau ao qual a propriedade de uma entidade pertence, comparando este grau a outros numa mesma escala. Vejamos em: João comprou muitos livros. A interpretação é que o número de livros que o João comprou está acima do padrão. A escala é, portanto, a escala dos cardinais - um, dois, três... Suponha que o padrão para comprar livros seja comprar dois livros; nesse caso, para que a sentença seja verdadeira, o João deve ter comprado mais do que dois livros.

No entanto, não nos interessa aqui a semântica do muito enquanto um quantificador de graus, mas o fato de que, em sentenças com o muito, sempre temos duas interpretações possíveis - contável e massiva - quando estamos diante de um singular nu ou de um nome de massa falso ("fake mass noun"). Dessa forma, procurando entender melhor o comportamento quantificacional do muito no $\mathrm{PB}$, fazemos uma comparação entre o muito/muitos e o que parece ser o par análogo no inglês, much/many.

\footnotetext{
${ }^{2}$ Usaremos a terminologia proposta por CHIERCHIA (2010) para nomes como furniture e mobilia. Work. Pap. Linguíst., 13(1): 51-64, Florianópolis, jan./mar, 2013
} 
Uma das mais claras distinções que se faz no estudo de línguas naturais sobre quantificadores é entre quantificação massiva e contável (ver, por exemplo, PELLETIER,1979; CARLSON,1998). Quantificadores massivos constituem expressões que denotam certa quantidade de massa, um agregado de massa. Por exemplo, much, em inglês, é um quantificador massivo, pois se combina apenas com nomes massivos, formando expressões como: much water e much cake. Em contraste, quantificadores contáveis constituem expressões que se combinam com nomes contáveis e denotam, informalmente, quantidades de coisas tomadas em suas unidades, exigem a escala de cardinais. Em inglês, many é um quantificador contável, pois forma expressões como: many boys e many cakes e * many cake é agramatical. Essa especificação pode ser verificada pela agramaticalidade das combinações apresentadas abaixo:

$$
\begin{aligned}
& \text { (5) a.*much boys } \\
& \text { b.*many water } \\
& \text { c.?? much boy } \\
& \text { d.*many boy }
\end{aligned}
$$

Portanto, em inglês, temos claramente o par much/many: many atua como o operador contável, pois quantifica apenas sobre nomes contáveis plurais, e much como o operador de massa (CHIERCHIA, 1998). Entretanto, podemos ter casos, como em (5c), no qual estamos diante do "moedor universal" ou "universal grinder". Conforme demonstrado por PELLETIER (1975), os nomes podem facilmente mudar da categoria contável para a categoria massiva, e essa mudança é autorizada pelo moedor universal, que transforma um nome contável em um nome de massa. "In principle, any count term that has physical objects in its extension can be used as a mass term given an appropriate context". ${ }^{3}$ (PELLETIER, 1975. p.176). De acordo com Pires de Oliveira e Souza (no prelo), o moedor universal é disparado

[...] por uma incompatibilidade de tipo semântico entre um nome singular - a steak 'um bife', an object 'um objeto', the object 'o objeto' - e uma estrutura de comparação que exige um nome cumulativo (plural ou massa), isto é, que tenha partes próprias ou pelo menos algum tipo de estrutura interna. Essa incompatibilidade irá desencadear a partição do indivíduo singular em suas (sub)partes próprias. (p.8).

Assim, em (5c), much boy, esperamos que a interpretação seja de mais partes de um garoto do que o padrão. No inglês, alguns nomes podem aparecer tanto em contexto contáveis como massivos, por ex.: paper, rock, stone, thought e judgment, porém uma vez usados para denotar indivíduos, como um contável, eles não poderão denotar massivamente e o uso para denotar indivíduos, em contextos de comparação, só ocorre com o nome plural. Assim, nas sentenças abaixo, em (6a), a interpretação só poderá ser de indivíduos, enquanto em (6b) a única interpretação possível é de massa.

(6) a. too many apples

b. too much apple

\footnotetext{
${ }^{3}$ Tradução nossa: Em princípio, qualquer termo contável que tem objetos físicos na sua extensão pode ser usado como termo de massa num contexto apropriado. 
No PB, essa distinção entre quantificadores massivos e contáveis é talvez menos clara do que no par de quantificadores do inglês (apesar de, numa análise rápida, tratarmos o muitos como um operador contável e o muito como um operador especializado para massa), e isso nos leva à dúvida sobre o muito, dado que ele se combina tanto com predicados que são aparentemente contáveis como carro sem gerar uma sentença agramatical, quanto com predicados massivos como água:

(7) Tem muito carro na caçamba do caminhão.

(8) Júlio desperdiçou muita água.

Esse pode ser um indício de que muito não equivale a much, no inglês ou que a análise do inglês para much precisa ser repensada, ou será que temos, em (7), o moedor universal funcionando? Se vamos explicar a interpretação de volume possível para a sentença em (7), não podemos apelar para o moedor universal, porque ele irá gerar a interpretação de que tem mais partes de um dado carro do que a caçamba do caminhão pode suportar, essa não é a leitura que estamos querendo apreender. O que acontece na leitura de "moedor universal" é que na comparação há uma leitura de porções de um indivíduo que é obtida quando temos um predicado singular no escopo do comparativo. Essa situação gera uma incompatibilidade de tipo semântico e resulta na transformação do indivíduo singular no conjunto de suas partes.

E quanto ao muitos e many, eles teriam a mesma distribuição? Vejamos os contrastes nos exemplos a seguir:

(9) a. John has too many stones. (leitura cardinal)

b. João tem muitas pedras (leitura cardinal)

(10) a. John has too much stone. (leitura massiva)

b. João tem muita pedra. (leitura massiva e leitura cardinal)

(11) a. * John has too many stone.

b. João tem muitas pedra(s). (leitura cardinal)

(12) a. * John has too much stones.

b. *João tem muita pedras.

Note que many se combina apenas com predicado plural, como atesta a agramaticalidade de (11a) e a gramaticalidade de (9a). Note também que stone se combina tanto com many, numa sintaxe contável (com marcas de pluralidade), exemplo (9a), quanto com much, exemplo (10a). Assim, uma proposta bastante aceita para o inglês (BALE \& BARNER,2009; BARNER \& SNEDECKER, 2005) é a da ambiguidade para um número restrito de itens lexicais no inglês: quando um predicado como stone aparece em contextos de comparação sem morfologia de número, é um nome massivo ou não contável, quando aparece combinado com many $\mathrm{e}$ consequentemente com morfologia plural é um predicado plural, permitindo somente a leitura cardinal, isto é, a leitura de que há uma ou mais unidades bem definidas.

Quanto aos exemplos do PB, muitos se combina apenas com predicados plurais, como é o caso de (9b) e (11b). Em (11b), pedra é um predicado plural, apesar de a pluralidade aparecer marcada apenas no quantificador. Veja que não podemos ter (12b), em que o quantificador não apresenta marca de pluralidade, que só ocorre no nome. A supressão de marca morfológica de número é um fato generalizado no $\mathrm{PB}$ e tem sido enfocado frequentemente pela investigação sociolinguística por meio dos trabalhos de GUY Work. Pap. Linguíst., 13(1): 51-64, Florianópolis, jan./mar, 2013 
(1981) e SCHERRE (1988). Assim, temos a certeza de que o predicado que segue o quantificador muitos é sempre plural, como acontece com o many, mesmo que a marca morfológica não apareça no nome, somente no quantificador, portanto.

Por sua vez, o muito se mostra diferente do much, pois ao se combinar com predicados como pedra, (10b), gera interpretação massiva e contável, isto é, a sentença é verdadeira em duas situações distintas: o número de pedras que o João tem é maior do que o normal ou o volume/peso é maior. Esse problema de decidir se estamos diante de um predicado singular ou de um predicado massivo se coloca de uma maneira aguda porque, num primeiro olhar, não temos certeza sobre muito, já que ele é homófono de muito(s) e se combina com predicados que, em princípio, se comportam como contáveis sem gerar uma sentença agramatical e sem ter a interpretação característica dos massivos, que é a leitura não cardinal. Perceba que, uma vez que temos um predicado associado ao much, como em (10a), só temos leitura de massa. Esse é, na verdade, o critério para termos certeza de que o nome que segue much é massivo. Contudo, é sempre bom ter em mente o problema dos nomes de massa como mobilia e furniture, em inglês, que irão problematizar ainda mais essa descrição. Como então se comportam esse tipo de nome de massa - mobília, bagagem, prataria, etc. com muito e muitos?

(13) Limpei muitas mobílias de casa. (unidade)

(14) Tenho muita mobília na sala. (unidade, volume)

Em (13), só podemos estar falando de peças da mobília, ou seja, as unidades, por causa da presença do plural. Em (14), diferentemente do que é relatado para o inglês (BALE \& BARNER, 2009), a comparação é possível tanto entre as unidades de mobília quanto com outras medidas relevantes, por exemplo: o volume. Vejamos os dados do inglês:

(15) * There are too many furniture.

(16) There was too much furniture crowding every room. ${ }^{4}$

Em inglês, furniture apenas se combina com much, como mostra a agramaticalidade de (15). Já a sentença em (16) é gramatical, embora furniture seja um nome de massa e, como tal, só deveria aceitar comparações de escalas contínuas, ele aceita também leitura cardinal. Na seção seguinte, veremos que, para Bale \& Barner (2009), nomes de massa se dividem no léxico em duas classes: os que são não atômicos, água, e os que são atômicos, mobília. Isso permite que mobília possa ser comparada por suas unidades, mas também pelo volume, uma questão sobre a qual os autores predizem contrariamente: o nome de massa furniture só aceita comparação por número, em decorrência do sistema que eles propõem.

Em resumo, vimos, até agora, que é possível a interpretação massiva e contável de sentenças como em (17):

(17) Pedro carregou muito livro. (unidade, volume)

Além do mais, há os chamados "fake mass nouns" que admitem leitura cardinal e massiva, como é o caso de mobília. Veja:

\footnotetext{
4 Tradução nossa: Havia muita mobília lotando cada cômodo. Fonte: http://edition.cnn.com/2012/03/01/living/confessions-compulsive-declutterer/index.html 
(18) O João tem muita mobília. (unidade, volume)

Dessa forma, na próxima seção, examinaremos a semântica de sentenças do tipo de (17) e (18), no sentido de entender que tipo de comparação está sendo operada, trazendo para a discussão o teste proposto por Bale \& Barner (2009).

\section{O TESTE DA COMPARAÇÃO: BALE AND BARNER (2009)}

Em "The Interpretation of Functional Heads: Using Comparatives to Explore the Mass/Count Distinction", Bale e Barner argumentam que o melhor teste para detectarmos se estamos diante de um nome de massa ou um contável é observar seu comportamento nas sentenças comparativas: nomes contáveis só admitem interpretação cardinal, isto é, em que contamos o número de indivíduos; por sua vez, os nomes massivos são comparados utilizando escalas não cardinais, como volume ou peso, por exemplo. O nome de massa aceita escalas contínuas (densas, isto é, entre um ponto da escala e outro há um infinito de pontos intermediários), enquanto que o nome contável só aceita a escala cardinal, que é pontual ou discreta. Para usar um exemplo dos autores:

\section{(19)a. Esme has more chairs than Seymour has tables. \\ b. Esme has more water than Seymour has juice.}

Note que nas sentenças acima, a dimensão que está sendo comparada muda de acordo com a denotação dos nomes. Assim, em (19a), o número de cadeiras é comparado ao número de mesas. Em (19b), o volume de água é comparado ao volume de suco. As estruturas de comparação permitem classificar os nomes em termos da dimensão do que está sendo comparado, começando principalmente com a distinção entre nomes que permitem a comparação por número e aqueles que não aceitam.

Como dissemos anteriormente, semanticamente, muito e seus correlatos (muitos, pouco) estabelecem uma comparação: algo é muito ou pouco em relação a um padrão dado contextualmente. Dessa forma, é de se esperar que encontremos com muito o mesmo comportamento da comparação. Vamos analisar a seguinte sentença:

(20) Tem muito menino no carro. (cardinal e volume)

A sentença permite leitura contável e massiva. Suponhamos a situação do carro e que apenas dois meninos entraram, mas eles são bem gordos e juntos ultrapassam em muito o espaço do carro. A sentença em (20) é feliz nesse contexto e tem interpretação de massa, não importa o número de meninos (diferentemente do que aconteceria se tivéssemos um sintagma plural muitos menino(s)). Mas (20) também aceita a interpretação contável. Se, por exemplo, ao invés de apenas dois meninos, tivermos 15 meninos na mesma situação e esse número é maior do que o carro pode suportar. Temos uma semelhança com nomes como mobília:

(21) Tem muita mobília no carro. (cardinal e volume)

Podemos, com (21), comentar sobre o número de móveis que está dentro do carro ou sobre o volume da mobília. Nesse ponto, o teste proposto aponta para o seguinte: quando na leitura contável, carro tem leitura cardinal; quando comparado numa escala 
contínua, massiva, carro tem leitura de volume. Sendo assim, o muito é ambíguo. Veja que ao aplicarmos o teste da comparação proposto, veremos que há duas interpretações: (i) a cardinal e (ii) a interpretação não contável, na qual o que está em comparação são outras dimensões, como peso ou volume, mas não a cardinal. Dessa forma, o teste não foi suficiente para definir se estamos diante de um nome de massa ou contável.

Então, chegamos a diferentes resultados: ou o teste da comparação proposto também não é um bom critério para distinguir massa e contável, pois, como vimos, numa sentença como em (20) as duas interpretações são possíveis, e o que vai determinar o critério de comparação são as circunstâncias do uso; ou o teste da comparação funciona e, em sentenças como em (20), estamos sempre diante de uma ambiguidade. Esse é o ponto que discutiremos na próxima seção. Antes disso, vejamos os desdobramentos da teoria proposta ainda em Bale \& Barner (2009).

Os autores propõem uma generalização quanto à distinção contável-massivo que segue: "Nenhum termo que pode ser usado numa sintaxe contável ${ }^{5}$ pode também ser usado numa sintaxe massiva para denotar indivíduos". 6 Segundo os autores, em inglês, esse quadro é problematizado pelo fato de o nome stone, sem morfologia de número, só aceitar comparação por volume, como vimos em (10a). Para os autores, stone tem uma contraparte contável, stones - portanto, a raiz stone parece ser contável. Assim, se um nome aparece em contextos tanto massivos quanto contáveis, ele vai denotar indivíduos como contável, mas nunca como um nome de massa, e denota massa na sintaxe de massa e nunca indivíduos. Por exemplo:

(22) a. too many stones. (apenas contável)

b. too much stone. (apenas massa)

Perceba que essa generalização não se aplica ao PB, uma vez que no exemplo em (20) temos acesso às duas interpretações, assim como no exemplo em (23):

(23) João comprou muito livro.

A sentença, portanto, vai contra a predição de Bale \& Barner (2009). Eles afirmam: "nossa abordagem prediz que línguas com a distinção massa-contável exibirão as mesmas generalizações do inglês, independente de diferenças de item-a-item em como as palavras são usadas." Não é isso o que os dados do PB mostram.

E como analisar sentenças como em (21)? Outra generalização discutida por Bale \& Barner (2009) diz o seguinte: "Some mass nouns (in the context of use) have individuals in their denotation and others do not." 8 Essa generalização diz respeito a alguns nomes em inglês, como furniture (mobília), que admitem a interpretação cardinal em contexto de comparação, como exemplificado em (24):

\footnotetext{
${ }^{5}$ Por sintaxe contável, podemos entender, por exemplo, a flexão de número.

${ }^{6}$ Tradução nossa: "No term that can be used in count syntax can also be used in a mass syntax to denote individuals."

${ }^{7}$ No original: "Our view predicts that languages with a mass-count distinction will exhibit the same generalizations as in English, regardless of item-by-item differences in how words are used. So long as a word can denote individuals as a mass noun, it should not appear also in count syntax." (249-250).

${ }^{8}$ Tradução nossa: Alguns nomes de massa (no contexto de uso) denotam indivíduos, enquanto outros não. Work. Pap. Linguíst., 13(1): 51-64, Florianópolis, jan./mar, 2013
} 
(24) John has more furniture than Mary. (apenas leitura cardinal)

Embora não discutida pelos autores, a sentença em (24) também tem uma leitura de volume. Não só no PB, mas acreditamos que também no inglês. Se for isso, a proposta semântica apresentada pelos autores faz predições incorretas. Esse é certamente o caso no PB:

(25) João tem mais mobília que Maria.

Esse é um dado inesperado para Bale \& Barner, porque nomes de massa que têm átomos deveriam permitir apenas comparações por unidades e não é isso o que ocorre em (25); os autores afirmam que nomes de massa que são objetos, como furniture, só podem receber leitura cardinal. É o caso de estarmos comparando tanto o número de unidades de mobília que o João possui a mais que a Maria, como também é o caso de haver uma comparação entre o volume de mobília de João em relação ao de Maria. Em sentenças com o muito parece acontecer o mesmo tipo de comparação:

(26) João despachou muita bagagem.

Num aeroporto, ao despachar bagagem, o que importa não são as unidades de bagagem, mas sim o peso. Entretanto, também é possível, em (26) nos referirmos às unidades de bagagem, malas. Assim, nomes como mobília, bagagem, prataria, etc. parecem funcionar como os nomes contáveis e como nomes de massa em contexto de comparação no PB.

Bale \& Barner (2009) propõem em seu modelo uma explicação para o caso de nomes como furniture só aceitarem interpretações contáveis. No modelo proposto por esses autores, no léxico há dois tipos de raízes: as raízes não atômicos - que incluem os nomes contáveis como boy e os nomes de massa como water - e as raízes atômicas que incluem apenas os nomes de massa que têm átomos, como furniture. Além disso, os nomes vêm marcados no léxico como contáveis, representado por um "c" subscrito junto ao nome, $\sqrt{b o y}_{\mathrm{c}}$, e os nomes massivos vêm sem nenhuma marca: $V_{\text {water }} \mathrm{e}$ لfurniture. Há duas operações disponíveis: a operação de individualização e a de identidade. A individualização só ocorre com os predicados não atômicos e marcados como contáveis, e a operação de identidade ocorre com os nomes de massa. A operação de identidade garante que o nome raiz $\sqrt{\text { furniture, }}$ porque ele denota um reticulado atômico ${ }^{9}$, só irá permitir a comparação por número de exemplares. Enquanto que $\sqrt{ }$ water só terá a comparação por escalas não cardinais. Para além do fato de que há muito de estipulação nesse modelo, ele leva a predições incorretas, dado que a interpretação massiva é possível para furniture como é para mobília no português. Como explicar a leitura massiva nesse modelo? Não há nenhuma explicação na proposta de Bale \& Barner (2009).

\footnotetext{
${ }^{9}$ Um reticulado é uma estrutura matemática construída a partir de elementos atômicos (os contáveis) ou moleculares (massa) ou construídos por somas, sem átomos, e uma operação de soma. Sua utilização para representar os nomes plurais e de massa foi proposta por Link (1983) e desde então tem sido adotada na literatura em semântica, com modificações. 
Na próxima seção, discutiremos a hipótese da ambiguidade para o caso do muito e mostraremos que isso implica também uma ambiguidade generalizada para os nomes como livro, menino, etc.

\section{A (NÃO) AMBIGUIDADE}

Se levarmos em consideração que o muito ora tem como domínio massa ora contáveis, podemos afirmar que se trata de um quantificador ambíguo. Vejamos as seguintes sentenças:

(27) Tem muito aluno no corredor.

(28) Tem muitos alunos no corredor.

Tanto em (27) quanto em (28) temos acesso a uma mesma interpretação: de que o número de alunos no corredor está acima do padrão, ou seja, estamos falando que o número de unidades de alunos é maior do que um padrão dado contextualmente para alunos no corredor. A sentença em (27), entretanto, é ambígua entre essa leitura e uma leitura massiva, já discutida em sentenças anteriores, em que o que importa não é o número de alunos, mas seu volume ou peso. Imagine que o corredor é bastante estreito e há dois alunos bem gordos.

Dessa forma, podemos afirmar que (27) é um reflexo da sentença em (28) sem os morfemas de plural em muitos e alunos. Isso explicaria a interpretação contável. Esse é

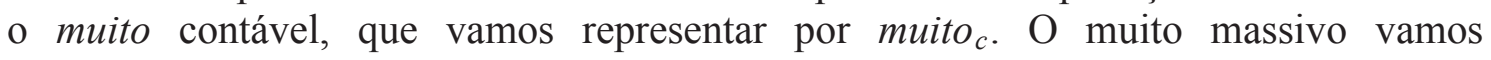
representar sem subscritos. Essa é a hipótese da ambiguidade do muito, embora superficialmente só vejamos um muito, temos, na verdade, muito que seleciona nomes de massa e muito ${ }_{c}$ que seleciona nomes contáveis e é o mesmo que aparece em muitos; temos, portanto, dois quantificadores, o massivo e o contável. Isso ocorre devido ao processo bastante comum no PB de perda de morfema de plural. Como acontece com os nomes em determinadas posições sintáticas, o mesmo processo também aconteceria com o muito.

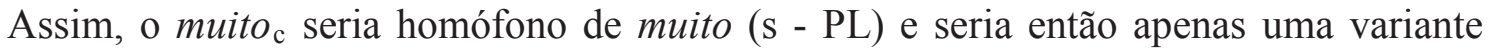
dessa outra forma. Haveria ainda um outro muito que só se combina com nomes massivos. Logo, temos tanto interpretação massiva quanto contável em sentenças como em (27), porque teríamos ali uma ambiguidade do item muito. Para que isso seja possível, o nome sob o escopo do quantificador precisa ser plural em interpretações cardinais, e um nome de massa quando tivermos leitura massiva. Dessa forma, não só o muito é ambíguo, mas também todos os nomes nus que aparecem sob o seu escopo. Assim, no PB aluno, quando sob o escopo de muito, ora é um predicado plural ora é um predicado massivo. Logo, duplicamos todos os nomes, temos menino contável plural, menino contável singular e menino massivo.

Essa não é uma hipótese econômica, mas pode ser que seja o caso. Entretanto, que tipo de problema ela coloca? Um ponto que essa hipótese precisa explicar é porque há interpretação plural, se não há nenhuma informação na sentença que indique isso. Por exemplo:

(29) Os último aluno saiu.

(30) O último aluno saiu.

Work. Pap. Linguíst., 13(1): 51-64, Florianópolis, jan./mar, 2013 
Em (29), temos a interpretação plural, pois o plural está expresso no determinante. Veja que sem a presença do morfema na sentença, não podemos ter a pluralidade. Então, como podemos admitir que muito seja também muitos, se não há nenhuma informação sentencial de plural? Trabalhos linguísticos já citados anteriormente (GUY (1981); SCHERRE (1988), entre outros) mostram que a perda de morfema de plural no PB só ocorre no nome e não no elemento mais à esquerda, no caso de (30), o determinante, que é um item funcional. Então esse não pode ser o caso para os sintagmas quantificados que estamos estudando, afinal o esperado é que o plural se mantenha no quantificador.

Outra questão é que, segundo essa hipótese, deveria se esperar que a sentença abaixo fosse gramatical:

(31) *Tem muito alunos no corredor.

Se o muito é ambíguo e carrega as informações de plural de muitos, ele deveria se combinar perfeitamente com alunos, que é plural, mas não é isso o que ocorre.

Essa hipótese parece aceitável por dar conta das duas interpretações possíveis em sentenças com o muito. Porém, parece ser barrada quando confrontada com outros dados do PB. Como pudemos notar, a hipótese da ambiguidade carrega alguns problemas. Uma hipótese que parece apontar para uma completa ambiguidade no sistema nominal é complicada do ponto de vista da plausibilidade psicológica, pois isso gera um problema para a aquisição da língua materna. Como é que a criança vai adquirir esses conceitos? Como ela vai adquirir a distinção contável-massivo no PB se todo o sistema nominal é ambíguo? Vamos ter que dizer que todos os nomes contáveis são ambíguos, eles podem ter leitura massiva ou contável. Só assim, explicamos como árvore pode apresentar as duas leituras no contexto de comparação. E por que os nomes massivos não seriam também ambíguos entre contável e massivo? Afinal, em sentenças com nomes massivos, a interpretação contável não é acessada, como em:

(32) Tem muito leite no meu café.

(33) Luiza perdeu muito sangue.

Uma hipótese proposta por Pires de Oliveira e Souza (no prelo) trata nomes como sangue e leite como nomes de massa que não têm átomos naturais ${ }^{10}$ e que têm sempre interpretação contínua (de volume ou peso), se combinando perfeitamente com o muito. Ainda segundo essa hipótese, o muito é um quantificador não contável, isto é, permite diferentes escalas contínuas e discretas (cardinal). De fato, não podemos ter uma quantificação com muito em que só haja interpretação contável, é sempre possível achar um contexto em que a leitura é de peso ou volume:

(34) Ele tem muita caneta no bolso.

(35) Tem muita cerca nesse terreno.

(36) João levou muita bagagem.

\footnotetext{
${ }^{10}$ Conceito que aparece em Rothstein (2010) para distinguir o domínio natural do domínio linguístico ou conceitual. Essa distinção é necessária porque há certos nomes que embora sejam contáveis - e, portanto, atômicos no domínio do linguístico -, não têm átomos naturais no mundo. Por exemplo, reta é um nome contável, podemos dizer duas retas, mas não há uma unidade no mundo que conte como reta independentemente do contexto, e qualquer pedaço de reta conta como uma reta.
} Work. Pap. Linguíst., 13(1): 51-64, Florianópolis, jan./mar, 2013 
Nas três sentenças acima, são possíveis tanto a interpretação cardinal quanto a massiva. Podemos afirmar que sempre que uma sentença apresenta possibilidade de interpretação contável do predicado, há também uma interpretação massiva. Muito disponibiliza sempre a interpretação não contável, que é impossível com muitos. Essa parece ser uma generalização correta. Quanto ao caso de nomes como bagagem, em (36), acontece que através das línguas nomes massivos podem ser comparados por diferentes escalas e caso sejam naturalmente atômicos podem também ser comparados via cardinalidade, o que significa que não há dois tipos de nomes massivos.

O chamado singular nu - nomes como livro, carro, menino, etc. - é massivo. A diferença entre os nomes de massa "tradicionais" e o singular nu é que sua raiz permite uma versão contável, ao passo que as raízes dos nomes de massa não permitem (*águas ${ }^{11}$ ). Logo, ele pode ser comparado tanto através de escalas contínuas quanto a cardinal. Aqueles que denotam aglomerados com átomos naturais (mobília) irão permitir comparação por quantidade de indivíduos atômicos, quando essa for a comparação relevante no contexto, e se comportam como os nomes massivos naturalmente atômicos; assim, a diferença entre o singular nu no PB e mobília ou furniture é que menino tem uma versão contável que aparece no plural em meninos, ao passo que furniture ou mobília não têm.

Essa hipótese parece indicar para uma solução unificadora para o caso do muito, em detrimento da hipótese da ambiguidade, que é sempre mais dispendiosa e, por isso, só deve ser assumida caso não seja possível uma explicação unificadora.

\section{CONSIDERAÇÕES FINAIS}

A partir do que foi exposto, somos levados a tirar algumas conclusões. Primeiramente, os dados apresentados mostraram que muitos é um quantificador especializado para predicados plurais, tendo como correspondente, no inglês, many. Lembrando que o muitos opera sobre plurais mesmo que a marca morfológica não apareça no nome, somente no quantificador, portanto. Assim sabemos que o que quer que se combine com muitos é plural. Se o sintagma for plural, não há outra alternativa a não ser a interpretação cardinal. Já o muito não é correspondente ao much, no inglês. O much se combina principalmente com nomes de massa e também com nomes como furniture. Também, com certa restrição, a nomes como stone, porém uma vez associados ao much, esses nomes não podem denotar unidades. Mas esse não é o caso do português. Predicados associados ao muito, seja carro, pedra ou mobília, geram interpretação massiva e contável, isto é, a sentença é verdadeira em duas situações distintas: o número é maior do que o normal ou o volume/peso (ou outra medida não cardinal) é maior.

Vimos também que se queremos explicar a interpretação de volume possível para as sentenças, não podemos apelar para o moedor universal, porque ele irá gerar somente a interpretação de que partes um dado objeto é maior do que o padrão. Além do mais, vimos que os nomes de massa que não têm átomos naturais, como água, têm sempre

\footnotetext{
${ }^{11}$ A única possibilidade de interpretarmos é se tivermos algum tipo de classificador escondido e cuja cardinalidade está sendo comparada: João bebeu muitos tipos de água, muitas garrafas de água. Nesse caso temos um nome contável medindo a substância água.

Work. Pap. Linguíst., 13(1): 51-64, Florianópolis, jan./mar, 2013
} 
interpretação contínua (de volume ou peso) e se combinam perfeitamente com muito. Concluímos que o comportamento do singular nu e dos nomes de massa atômicos na comparação mostra que as generalizações de Bale \& Barner não se sustentam para o PB.

Do ponto de vista teórico, apresentamos a questão de estarmos diante de uma ambiguidade, em relação ao muito, o que nos levaria ao fato de que nomes como menino às vezes é massa e às vezes é contável - paralelamente muito às vezes é um quantificador massivo e às vezes é um quantificador contável. No entanto, argumentamos contrariamente, mostrando que uma completa ambiguidade no sistema nominal é complicado do ponto de vista da plausibilidade psicológica. O que também gera problemas para a aquisição da língua, já que a criança tem que adquirir esses conceitos. Assim, fica difícil se no PB todo o sistema nominal é ambíguo. Desse modo, concluímos que a hipótese da ambiguidade não se sustenta perante os argumentos apresentados. Parece-nos que a proposta de estarmos sempre diante de uma única interpretação de menino e muito é sempre um quantificador não contável é mais plausível, como fazem Pires de Oliveira e Souza (no prelo).

Em que pese o fato de esse trabalho não propor outra explicação para o fenômeno, o muito, como vimos, só se combina com nomes nus, então uma proposta explicativa para esse caso deve olhar de perto a semântica desses nominais. Por exemplo, de acordo com a proposta de Pires De Oliveira e Rothstein (2011), para os nomes nus, ele sempre denota a espécie e é construído a partir do predicado raiz que não tem átomos delimitados. Assim, espera-se que o singular nu no PB possa sempre ter leitura de volume, como vimos que é o caso dos exemplos apresentados aqui. Sendo assim, outra solução para o caso do muito é afirmar que ele só quantifica sobre a espécie. A avaliação desta hipótese está em andamento e deve ser apresentada posteriormente, em trabalhos futuros.

\section{REFERÊNCIAS}

BALE, A. C.; D. BARNER. The interpretation of functional heads: using comparatives to explore mass/count distinction. Journal of Semantics, v. 26, p. 217-252, 2009

BARNER, D.; SNEDEKER, J. Quantity judgments and individuation: evidence that mass nouns count. Cognition, v. 97, p. 41-66, 2005

Children's early understanding of mass-count syntax: individuation, lexical content, and the number asymmetry hypothesis. Language Learning and Development v. 2, p. 163-94, 2006

CAMACHO, R. G. \& PEZATTI, Erotilde G. As subcategorias nominais contável e nãocontável. In: KATO, Mary A. (org.). Gramática do Português Falado. vol. 5. Campinas: Editora da Unicamp, 1996, p. 155-183.

CARLSON, G. Reference to kinds in English. PhD dissertation, University of Massachusetts at Amherst, distributed by GSLA, 1977.

Names, and what they are names of. Behavioral and Brain Sciences, v.21 (1) p.69-70, 1998 
CARlsON, G. N.; PELlETIER, P. J. (Eds.). The Generic Book. Chicago: The University of Chicago Press, p. 176-223. 1998

CHIERCHIA, G. 1995. Individual level predicates as inherent generics. In: CHIERCHIA, G. Plurality of mass nouns and the notion of 'semantic parameter. In: S. Rothstein (ed.), Events and grammar. 1998, p. 53-103. Dordrecht: Kluwer

$\overline{339-405}, 1998$

Reference to kinds across languages. Natural Language Semantics, v. 6, p. . Semântica. Campinas: Ed. da UNICAMP; Londrina: EDUEL, 2003.

.Mass nouns, vagueness and semantic variation. Synthese. 2010.

CRESSWELL, Maxwell. The semantics of degree. In: Montague Grammar, Barbara Partee (ed.). New York: Academic Press, p. 261-292, 1976

GUIMARÃES, M. R. Dos intensificadores como quantificadores: os âmbitos de expressão da quantificação no português do Brasil. (Tese de Doutorado). Curitiba, 2006.

GUY, G. R. Linguistic variation in Brazilian Portuguese: aspects of the phonology, syntax and language history. Ph.D.Dissertation. University of Pennsylvania, 1981.

HACKL, M. Comparative quantifers. PhD Thesis, MIT, 2000.

KLEIN, E. A Semantics for Positive and Comparative Adjectives', Linguistics and Philosophy, vol. 4, p.1-45, 1980

LANDMAN, F. On the mass-count distinction. m.s. Tel Aviv University. 2006.

LØNNING, J.T. Mass terms and quantification. Linguistics \& Philosophy, p. 10-1, 1$52,1987$.

PELLETIER, J. Non-singular reference: some preliminaries. Philosophia, v.5, p.451465, 1975.

PIRES DE OLIVEIRA, R.; SOUZA, De. L. M. O singular nu e a comparação: uma proposta de derivação semântica. No prelo.

PIRES DE OLIVEIRA, R.; ROTHSTEIN, S. Bare Singular noun phrases are mass in Brazilian Portuguese. Lingua, 2011(121), p. 2153-2175.

ROTHSTEIN, S. Counting and the mass-count distinction. Journal of Semantics, v.27 (3), 343-397, 2010a.

ROTHSTEIN, S., Bare nouns semantics, kind interpretations and the Universal Grinder. In: Conference at Bare Nominals and Genericity Conference Paris, 2010b.

SCHERRE, M. M. P. Reanálise da concordância nominal em português. Rio de Janeiro, 555 p. (Doutorado em Linguística) Faculdade de Letras, UFRJ, 1988.

SCHMITT, C., MUNN, A. Against the nominal mapping parameter: bare nouns in Brazilian Portuguese. In: Proceedings of NELS 29, 1999, p. 339-353.

SCHMITT, C.; MUNN, A. The syntax and semantics of bare arguments in Brazilian Portuguese. Linguistic Variation Yearbook, v.2, p: 253-269, 2002.

Recebido: 09/05/2013

Aceito: 30/06/2013

Work. Pap. Linguíst., 13(1): 51-64, Florianópolis, jan./mar, 2013 